\title{
Artelogie
}

Recherche sur les arts, le patrimoine et la littérature de l'Amérique latine

17 | 2021

Transformaciones en Cuba contemporánea: cultura y sociedad

\section{Texto de solidaridad con el historiador y politólogo uruguayo Gerardo Caetano}

\section{(2) OpenEdition}

\section{Journals}

Edición electrónica

URL: https://journals.openedition.org/artelogie/10285

DOI: 10.4000/artelogie.10285

ISSN: 2115-6395

Editor

Association ESCAL

Referencia electrónica

«Texto de solidaridad con el historiador y politólogo uruguayo Gerardo Caetano», Artelogie [En línea]

17 | 2021, Publicado el 27 septiembre 2021, consultado el 15 septiembre 2022. URL: http://

journals.openedition.org/artelogie/10285 ; DOI: https://doi.org/10.4000/artelogie.10285

Este documento fue generado automáticamente el 15 septiembre 2022.

All rights reserved 


\section{Texto de solidaridad con el historiador y politólogo uruguayo Gerardo Caetano}

Los abajo firmantes se solidarizan con el historiador y politólogo uruguayo Gerardo Caetano, quien luego de su participación, el día 31 de agosto de este año, a una actividad académica en el Instituto Militar de Estudios Superiores de su país, recibió varios insultos y fue víctima de intimidación con ataques (orales y escritos, en redes sociales y en la prensa) a su trabajo y a su persona. Doctor en Historia por la Universidad Nacional de La Plata (Argentina), catedrático en la Universidad de la República y, desde 2005, coordinador académico del Observatorio Político del Instituto de Ciencia Política de la Facultad de Ciencias Sociales, del que fue director entre el 2000 y el 2005, Caetano ha participado en varias actividades académicas y cotutelas de tesis doctorales en diferentes países, entre otros Uruguay y Francia.

En esa actividad convocada por la Comandancia General del Ejército, Caetano afirmó, dirigiéndose a los militares : "Cuando me enteré de esta iniciativa, no pude menos que apostar a la esperanza". "La historia no debe ser ancla, sino catapulta para el futuro. Celebro muy particularmente poder dirigirme a ustedes".

2 Caetano fue escuchado con atención y articuló su presentación sobre algunos puntos en torno a la cuestión de la violación de las leyes y el no respeto de la democracia y los derechos humanos. Y lo enunció así: "No hay razón alguna que justifique la violación de la Constitución. Y no hay ninguna razón para ningún actor".

El historiador continuó así :

"Del mismo modo en que no creo en la teoría de los dos demonios, no creo que el único terrorismo haya sido el terrorismo de Estado, pero reitero que fue el más ilegítimo. Porque no puede ser que el Estado se vuelva contra sus ciudadanos para cometer tropelías inconcebibles, como la desaparición forzada de personas, la 
tortura, el sometimiento de civiles a la arbitrariedad de prácticas de justicia militar indebida, la coacción a las libertades individuales fundamentales, la apropiación de funciones políticas que solamente el soberano puede transferir".

Caetano sostuvo tener presente que los oficiales que lo escuchaban no habían participado en esos "actos abominables" propios a lo que él considera "terrorismo de estado". Y les pidió a los capitanes y mayores que no asumieran como propios esos hechos.

"Una institución genera historia, pero tiene que seleccionar qué historias hereda y cómo lo hace [...]. Lo que fue terrorismo, fue terrorismo. Y deben ser condenados sus protagonistas. Lo que fue terrorismo -estatal o no estatal- debe ser condenado". El politólogo defendió la necesidad de que la Justicia actúe en estos casos y de que se continúe la búsqueda de los cuerpos de los desaparecidos.

"Hay compatriotas que no saben dónde están los restos de sus familiares. Y lamentablemente hay quienes, también compatriotas, saben dónde están esos restos. Hay un derecho inalienable para que esos actos aberrantes sean objeto de justicia, no hay República plena sin justicia”.

5 G. Caetano sostuvo también la cuestión de los límites de la violencia del estado. "No deben ser aplicadas órdenes que signifiquen la violación de los derechos humanos, de la Constitución o de la ley" porque, señaló :

"No debe haber una frontera que nos divida a civiles y militares" (...) "El destino que tenemos en común es el respeto irrestricto a los valores de la Constitución y de los derechos humanos. La República nos hermana. Por eso no puede haber partidización del ejército, no debe haberla".

Caetano se despidió señalando su apoyo a estas actividades impulsadas por el Ejército con la Universidad de la República como invitada y copartícipe.

"Mi mayor apuesta a esta iniciativa del comandante; sé que expresa la opinión de muchos otros, no sólo oficiales, generales, sino de integrantes de las nuevas generaciones del Ejército. No se me omite que seguramente hay quienes no están de acuerdo. La falta de acuerdo ante una iniciativa valiente es propia de la vida democrática".

8 La falta de acuerdo con su propuesta y su análisis de cómo debe funcionar la democracia comenzó a manifestarse en diferentes medios de comunicación. Esto es obvio y totalmente legítimo y es más fue totalmente admitido por Caetano en ese mismo discurso, como un diferendo que forma parte de la producción común de la historia. En un breve apartado sobre la construcción de la "memoria de la República", Caetano aseguró que ésta, tiene que ser plural y alejada de "relatos" o mitologías políticas. Pero también insistió que los historiadores no tienen, ni deben tener, el monopolio en la construcción de esa memoria.

Sin embargo, para la fortaleza y solidez del debate histórico es fundamental tener en cuenta las formas de discutir y la sinceridad en el respeto hacia las otras posiciones. No fueron así recibidas sus tesis en los artículos y comentarios que poco a poco siguieron a este evento en medios e internet. Solo daremos dos ejemplos de la tonalidad con la cual se respondió a estos propósitos, con la idea que podemos estar en acuerdo con uno u otro de los participantes de la discusión pero no podemos, so pena de recrear una verdadera guerra y no un debate civil, menospreciar su persona o desvalorizar a priori las ideas del dialogante por tener una posición diferente de la nuestra. 

ser publicada en el prestigioso semanario Busqueda de Montevideo $^{1}$, éste afirma :

"Así como Ud., operador de la guerra psicológica, se ha dirigido indirectamente a mí (como oficial superior del Ejército), le voy a contestar sus atrevidas y falaces expresiones, realizadas ante un auditorio de análisis histórico académico. "

"Esa es una parte de la verdad histórica, Ud. de "historiador y periodista" tiene tanto como yo de poeta. Como está mencionado al principio de ésta, al enemigo se le respeta como tal, aún en el fragor y descontrol del enfrentamiento violento, pues tiene el coraje y las agallas de llevar a cabo sus acciones; a quienes no respetamos moralmente son a los "guerrilleros del papel, de escritorio o de WhatsApp", quienes mediante un falso relato siembran veneno en la sociedad, particularmente "dando manija" a los jóvenes, explotando su juventud idealista y su inexperiencia de vida. $Y$ finalmente: nuestra fortaleza indestructible tiene como fuentes nuestra convicción, el espíritu militar, de cuerpo, el patriotismo y la confianza en quienes nos comandan, más allá de discrepancias puntuales; somos seres pensantes y analíticos, no robots que actúan mecánicamente; nuestra cohesión férrea tiene como base la disciplina militar."

11 Nos interesa destacar en la carta del Sr.Ferro su visión de la continuidad de la guerra y, al mismo tiempo, su representación de la sociedad donde habría "enemigos" y "guerrilleros" más que ciudadanos en desacuerdo, con lo cual se desplaza el conflicto civil al cultural :

"El enfrentamiento se desarrolla hoy día en el factor sociocultural (desde donde Ud. actúa); no hay más violencia física en esta etapa; pero sí hay violencia psicológica, usada con extrema sutileza, de la misma peligrosidad. El combate se desarrolla disolviendo a la sociedad, poniendo en duda sus valores y creencias; incidiendo sobre los programas de estudios de los institutos de enseñanza (falseando la historia tal cual Ud. hace); minimizando el valor de la familia; poniendo en duda la biología y sexualidad; cambiando groseramente el idioma; uso exagerado de ONG de dudoso origen; organizaciones sociales notoriamente de izquierda y financiamientos de sospechoso origen; radios comunitarias incitando a la separación/quiebre social; prensa y medios de comunicación diseminando información sesgada o medias verdades; proliferación de "sitios de la memoria" obviamente rememorando guerrilleros o militantes activos; operadores judiciales y fiscales cometiendo tropelías jurídicas que no cumplen las reglas básicas del derecho, procesando y condenando a miembros de las FF.AA; desjerarquizando los tradicionales festejos patrios; ataque sistemático a integrantes de las FF.AA. por el "pasado reciente"; y la falacia del "terrorismo de Estado"; usando muletillas y slogans facilongos de repetir..."

La idea de actualidad de la guerra o de pasaje de la guerra civil a la cultural no es nueva en algunos analistas políticos (ubicados claramente en la derecha del espectro político) y se constata en todo el continente americano, del sur al norte. Cabe recordar que tras la salida de los períodos autoritarios y de la década perdida de los ochenta del siglo pasado, en los años que siguieron se vivió un periodo de apertura hacia la participación democrática así como de desarrollo de las políticas culturales en América Latina e impulsión de políticas de promoción de la enseñanza desde la escuela hasta la universidad. Un tal desarrollo sociocultural (valga el término) fue acompañado del reconocimiento de derechos en diferentes dominios, entre los cuales los más importantes han sido los de pluralismo étnico y los de diversidad sexual (particularmente importante para el Uruguay), ya muy analizados en sendos números de nuestra revista. 

intelectualidad conservadora ( $\tan$ necesaria para una sociedad como las ideas transformadoras) frente a las paradojas de una realidad, como la actual, de mutaciones aceleradas y en tantos ámbitos diversos, de lo tecnológico o lo sexual, de las relaciones en la familia a las relaciones geopolíticas (sin ser exhaustivo), todo lo cual exige nuevos puntos de vista y reacciones. En la búsqueda de respuestas, la lógica de la Guerra Fría reaparece como Guerra Cultural.

En otro de los textos sobre el tema, Daniel García también en nota del 10 de septiembre de 2021 para el semanario Contexto $^{2}$, desmereciendo también lamentablemente los propósitos del historiador, afirma:

"Pero Caetano parece que sueña que en la Escuela Militar se den clases de pintura, crochet y que los jóvenes oficiales así como los venideros, se desliguen del pasado, lo repudien, desconozcan y condenen a quienes tuvieron que enfrentar a un enemigo, que hoy puede haber mutado en sus métodos, pero nunca ha renegado o abandonado sus objetivos.

La Guerra Fría puede haber terminado, pero la Revolución hoy ha tomado la vía Cultural como un medio para divulgar su filosofía, habiendo desarrollado una clara hegemonía cultural, así como se ha valido de nuevos Caballos de Troya que ya no son de madera, son de carne y hueso y eso los hace más peligrosos."

En un momento de crisis de las democracias latinoamericanas es necesario ahora más que nunca, poder expresar todas las ideas y convicciones de frente, como lo ha hecho con coraje Gerardo Caetano, pero de manera justamente plural, con respeto y sin bajezas ni ataques deslegitimantes o intimidatorios. No es un tema de verdad histórica solamente que está en juego sino, sobre todo, de formas del debate democrático. Las agresiones, los desprecios y los menosprecios, así como los juicios agresivos personales sin posibilidad de respuesta o de diálogo en un entorno razonable (a los que nos han acostumbrado, cierto, las redes sociales) son inaceptables en todo los casos $\mathrm{y}$, en particular, hacia este historiador, especialista de la política uruguaya. Autor de más de 150 publicaciones, sus trabajos sobre la larga marcha de la democracia en Uruguay, han sido reconocidos por sus pares entre las más importantes contribuciones al análisis y comprensión de la Historia de América y su pasaje del siglo XIX al XX.

Arijon Gonzalo (Cineasta, Francia)

Anegon Ignacio (Co-leader Team 2 Director FOCIS Center of Excellence Nantes University, Nantes, Francia)

Barrientos Tecún Dante (Profesor de la Universidad de Aix Marseille, Francia)

Benvenuto Andrea (Profesora, EHESS, Paris Francia)

Bodner Guillermo (Psicoanalista, SEP, Barcelona, España)

Boyer Amalia (Profesora de Universidad del Rosario, Colombia)

Caplán Raúl (Profesor de Universidad de Grenoble Alpes, Francia)

Cayuela Anne (Profesora de Universidad de Grenoble Alpes, Francia)

Copello Fernando (Profesor de la Universidad Le Mans, Francia)

Compagnon Olivier (Profesor de la Universidad de la Sorbona, Francia)

Dansilio Florencia (Investigadora del Instituto CREDA, Universidad de Paris 3, Francia)

Estrada Urroz Rosalina (Profesora Benemérita Universidad Autónoma de Puebla, México) 


\section{NOTAS}

1. Carta de Eduardo A. Ferro Bizzozero del 16 al 22 de Setiembre de 2021, Busqueda № 2140 en Debate sobre la historia reciente

2. Nota de Daniel García del 10 de septiembre de 2021, Semanario Contexto, Montevideo.

\section{RESÚMENES}

Texto de solidaridad con el historiador y politólogo uruguayo Gerardo Caetano, quien luego de su participación, el día 31 de agosto de este año, a una actividad académica en el Instituto Militar de Estudios Superiores de su país, recibió varios insultos y fue víctima de intimidación con ataques (orales y escritos, en redes sociales y en la prensa) a su trabajo y a su persona. Doctor en Historia por la Universidad Nacional de La Plata (Argentina), catedrático en la Universidad de la República y, desde 2005, coordinador académico del Observatorio Político del Instituto de Ciencia Política de la Facultad de Ciencias Sociales, del que fue director entre el 2000 y el 2005, Caetano ha 
participado en varias actividades académicas y cotutelas de tesis doctorales en diferentes países, entre otros Uruguay y Francia.

Texte de solidarité avec l'historien et politologue uruguayen Gerardo Caetano qui, après sa participation, le 31 août dernier, à une activité universitaire à l'Institut militaire des hautes études de son pays, a reçu plusieurs insultes et a été victime d'intimidations avec attaques (orales et écrites, dans les réseaux sociaux et dans la presse) contre son travail et contre sa personne. Docteur en histoire par l'Université nationale de La Plata (Argentine), professeur à l'Université de la République (UDELAR) et dès l'année 2005, coordinateur académique de l'Observatoire politique de l'Institut de science politique de la Faculté des sciences sociales (Montevideo), de laquelle il a été directeur entre 2000 et 2005, Caetano a participé à diverses activités académiques et co-tutelles de thèses de doctorat dans différents pays, entre autres l'Uruguay et la France..

ÍNDICE

Mots-clés: Gerardo Caetano, Eduardo A. Ferro Bizzozero, Daniel García, Uruguay

Palabras claves: Gerardo Caetano, Eduardo A. Ferro Bizzozero, Daniel García, Uruguay 